\title{
A tribute to Schwarzbach (1968): Recent ice age hypotheses
}

\author{
Jürgen Ehlers \\ Hellberg 2a, 21514 Witzeeze, Germany
}

Correspondence: Jürgen Ehlers (jehlersqua@outlook.de)

Relevant dates: $\quad$ Received: 1 August 2021 - Revised: 20 August 2021 - Accepted: 5 November 2021 Published: 17 December 2021

How to cite:

Ehlers, J.: A tribute to Schwarzbach (1968): Recent ice age hypotheses, E\&G Quaternary Sci. J., 70, 235-237, https://doi.org/10.5194/egqsj-70-235-2021, 2021.

Special issue statement. This article is part of a special issue published on the occasion of the 70th anniversary of $E \& G$ Quaternary Science Journal (EGQSJ). The special issue celebrates the journal's notable contribution to Quaternary research by revisiting selected milestone articles published in the long history of EGQSJ. The German Quaternary Association (DEUQUA) presents translations of the originals and critical appraisals of their impact in tandem anniversary issues of DEUQUASP and EGQSJ, respectively.

Original article: https://doi.org/10.3285/eg.19.1.21

Translation: https://doi.org/10.5194/deuquasp-3$79-2021$

In Germany, Martin Schwarzbach is often regarded as the "father of palaeoclimatology". He published the results of his work in his book Das Klima der Vorzeit (Climate of the past). This standard work, which has gone through several editions, was first published in 1950. A Russian edition followed after 5 years, and a few years later the book was also translated into English. Schwarzbach dealt with the entire field of palaeoclimatology, and a large part of his work was devoted to the identification of the numerous climate indicators in the rocks of the Earth. His paper in Eiszeitalter und Gegenwart deals with only one aspect of his research, the ice ages, and specifically with the more recent ice age hypotheses.

Today, one can hardly imagine the technical difficulties Schwarzbach had to contend with at that time in order to work on a global scale. There were no computers and, importantly, there was no internet to gather new scientific information from all over the world. Schwarzbach nevertheless succeeded in gaining an overview of the palaeoclimatic development of the Earth and presenting it in an easily accessible way.

In 1968, there was no doubt that major ice ages had occurred repeatedly in the course of Earth's history. What was missing was a generally accepted timescale for the ice ages and also a comprehensive explanation for their causes. It was well known that there had been long-, medium-, and shortterm climate fluctuations in the course of Earth's history. But only the traces of the more recent fluctuations within the last 600 million years were accessible for investigation. Not much was known about what had happened in the preceding six-sevenths of Earth's history, in the Precambrian. Nevertheless, the number of ice age hypotheses grew.

The article of Schwarzbach (1968) is a critical discussion of the then current hypotheses. The idea that the continents had changed their position in the course of Earth's history had been brought into play by Alfred Wegener long before, but as his theory had been rejected by his influential opponents Hans Cloos and Hans Stille, hardly anyone in Germany believed in it anymore (Hallam, 1975). Schwarzbach brings this theory back into the discussion. He points out that the shifting of the continents in the course of Earth's history is hardly doubted by geoscientists in Australia and in North and South America.

He briefly discusses the expansion of the Earth, which the physicist Pascual Jordan had postulated. At first glance, it seemed like an interesting idea that might explain, for example, the drifting apart of the continents. But this hypothesis contradicted geological findings. 
Schwarzbach calls the idea put forward by geologist Johann Steiner as a possible cause for the formation of the ice ages "quite a funny hypothesis". According to Steiner, it takes 280 million years for our solar system to circle once around the centre of our Milky Way. The last three great ice ages were also separated from each other by roughly $280 \mathrm{mil}-$ lion years. But that might still be coincidence. The assumed change in the gravitational constant in the course of this cycle was too small to trigger the ice ages.

Also, the importance of volcanic dust for climate fluctuations was considered rather small. Schwarzbach cites the Krakatau eruption of 1895 as evidence. And even the Tambora eruption of 1815, which was followed a year later by the so-called "year without a summer", did not result in any longer-lasting climatic consequences. And the alleged catastrophic volcanic eruption on the sub-Antarctic Thompson Island, with which the climatologist Lamb (1967) explained a series of cool years in New Zealand and southern Chile in 1967, was unproven. Today, we know that not only did the eruption never happen but also the island never existed (Dreyer-Eimbcke, 1990).

Schwarzbach knew that if one wanted to understand the ice age, one needed reliable age data. Milankovitch's radiation curve had offered a first possibility. But the fluctuations of Earth's orbital elements had existed at all times, even when there were no glaciers on Earth. Radiometric age determinations now provided a method to check at least the youngest part of the curve. At first it looked as if the results of the dating could be reconciled with the radiation curve. But the last glaciation maximum, for which a radiometric age of 18000 years had been determined in the USA, seemed to be 7000 years younger than predicted by Milankovitch. In addition, the age known at that time of the last interglacial, the Eemian, of $70 \mathrm{kyr}$ (Flint and Rubin, 1955) was 50 kyr younger than analysed shortly afterwards (Shackleton, 1969).

Apart from that, there was another problem. The continental stratigraphical sequences were too short and included too many gaps. But there were other, more complete sediment series provided by deep-sea drillings. Emiliani (1955) was able to publish a rough temperature curve for the most recent parts of the Pleistocene (Imbrie and Palmer Imbrie, 1979).

It was only the realisation that the sea floor was moving and thus driving plate tectonics (sea floor spreading) that brought continental drift back to the fore (Dietz, 1961; Vine, 1966). But in 1968 this realisation had not yet reached Germany. Very soon it would become clear that the study of drill cores from the Atlantic and the Pacific opened up the possibility of establishing a new basic framework for the climatic history of the Quaternary. But that was after 1968. Isotope stratigraphy based on deep-sea drillings was still in its infancy at the time.

However, Earth scientists had already begun to look for traces of past climate fluctuations in the ice itself. The first deep borehole in an ice sheet was drilled at Camp Cen- tury, an American military base on Greenland, in 1966. Lowresolution uncertainties about dating and lack of knowledge about the ice flow behaviour at the site of the drilling limited the value of the results. However, the borehole reached deep enough to yield an important first result. In the deepest samples from the borehole, ice was found that had been formed during the last interglacial. This proved that the Greenland ice sheet had not completely melted during the Eemian warm stage (Langway, 1967). And the borehole had shown the potential of studying ice cores (Dansgaard et al., 1969).

The first deep borehole in Antarctic ice was drilled at the American Byrd Station in 1968. When the results were compared with those from Camp Century, it became apparent that there was a strong correspondence between the cores from Antarctica and the Greenland cores. Our current understanding of the chronology of at least the Pleistocene dramatically improved with the first ice core drillings in Greenland in 1966 and in Antarctica in 1968, which showed the potential of studying these high-resolution archives (Dansgaard et al., 1969).

Together with the results of drill cores in the North Atlantic, short-term Dansgaard-Oeschger (D-O) cycles of 1000-2000 years with temperature jumps of $12^{\circ} \mathrm{C}$ (Rahmstorf, 2003) and enormous instabilities of ice shields, socalled Heinrich events, linked to some of the D-O events are part of the high-resolution event stratigraphy of the last $100 \mathrm{kyr}$ (INTIMATE). Antarctic ice cores ranging down to $800 \mathrm{ka}$ (Wolff, 2008) provide data on the former greenhouse gas concentrations $\left(\mathrm{CO}_{2}, \mathrm{CH}_{4}\right)$ in relation to temperature change, allowing researchers to establish better climate models with supercomputers.

This was far beyond Schwarzbach's knowledge. However, with his considerations on a "multilateral ice age formation" he emphasised the unsatisfactory conclusions of many of the then modern ice age hypotheses. As the sun's radiant force must have remained roughly constant over 600 million years, with the exception of minor fluctuations, the climate course must have been influenced by other factors according to Schwarzbach: "the profound geographical changes in the distribution of land and sea and in the relief, i.e. the constantly changing face of the Earth, changes in the $\mathrm{CO}_{2}$ and water vapour content of the atmosphere, periodic changes in the elements of Earth's orbit, and dark clouds in space, but also continental drift and many other factors". The interaction of all these factors was seen by Schwarzbach as the cause of the small and large climate fluctuations in Earth's history in the sense of a multilateral ice age development. Moreover, Schwarzbach regarded continental drift as a main factor beside primary variations in solar radiation. Thus, he already had a deep understanding of the complexity of the climate system that is quite similar to our modern one, where the effects of plate tectonics and weathering processes (Raymo and Rudddiman, 1992) together with changes in Earth's orbit elements (Hays et al., 1976) provide reasonable explanations of the general pace of climate change (Ruddiman, 
2014). Schwarzbach had already emphasised positive feedbacks when he regarded that "the initial formation of larger ice masses in the polar region certainly plays a decisive role due to the secondary cooling 'self-reinforcing' effects that are automatically coupled with it". Schwarzbach was openminded when he did not even exclude the possibility of autocyclic processes and the "possibility that long-term and medium-term climate fluctuations may occur relatively independently of each other".

In 1968, Schwarzbach had not given up hope that a single, all-encompassing explanation for the phenomenon of the ice ages might be found. However, this has not yet been achieved (Ehlers et al., 2016).

Acknowledgements. I thank Phil Gibbard for his help with the translation. The anonymous reviewer made valuable suggestions.

Financial support. The article processing charge was funded by the Quaternary scientific community, as represented by the host institution of EGQSJ, the German Quaternary Association (DEUQUA).

Review statement. This paper was edited by Frank Preusser and reviewed by one anonymous referee.

\section{References}

Dansgaard, W., Johnsen, S., Møller, J., and Langway, C.: One Thousand Centuries of Climatic Record from Camp Century on the Greenland Ice Sheet, Science, 166, 377-381, 1969.

Dietz, R. S.: Continent and ocean basin evolution by spreading of the sea floor, Nature, 190, 854-857, https://doi.org/10.1038/190854a0, 1961.

Dreyer-Eimbcke, O.: Mythische und imaginäre Inseln des Atlantiks im Kartenbild, Mitteilungen der Geographischen Gesellschaft in Hamburg, 80, 651-681, 1990.
Ehlers, J., Hughes, P., and Gibbard, P. L.: The Ice Age, Wiley, Blackwell, Chichester, 548 pp., 2016.

Emiliani, C.: Pleistocene temperatures, J. Geol., 63, 538-578, available at: https://www.jstor.org/stable/30080906 (last access: last access: 6 December 2021), 1955.

Flint, R. F. and Rubin, M.: Radiocarbon dates of pre-Mankato events in eastern and central North America, Science, 121, 649658, 1955.

Hallam, A.: Alfred Wegener and the Hypothesis of Continental Drift, Sci. Am., 232, 88-97, available at: https://www.jstor.org/ stable/24949733 (last access: 6 December 2021), 1975.

Hays, J. D., Imbrie, J., and Shackleton, N.: Variation in the Earth's orbit: Pacemaker of the Ice Ages, Science, 194, 1121-1132, https://doi.org/10.1126/science.194.4270.1121, 1976.

Imbrie, J. and Palmer Imbrie, K.: Ice Ages - Solving the mystery, Harvard University Press, 224 pp., 1979.

Lamb, H. H.: The Problem of Thompson Island, Brit. Antarct. Surv. B., 13, 85-88, 1967.

Langway, C. C.: Stratigraphic analysis of a deep ice core from Greenland, CRREL Research Report 77, 185 pp., 1967.

Rahmstorf, S.: Timing of abrupt climate change: A precise clock, Geophys. Res. Lett., 30, 1510, https://doi.org/10.1029/2003GL017115, 2003.

Raymo, M. E. and Ruddiman, W. F.: Tectonic forcing of late Cenozoic climate, Nature, 359, 117-122, 1992.

Ruddiman W. F.: Earth's Climate: Past and Future, W.H. Freeman and Sons, New York, 445 pp., 2014.

Schwarzbach, M.: Das Klima der Vorzeit, Enke, Stuttgart, 211 pp., 1950.

Shackleton, N. J.: The last interglacial in the marine and terrestrial records, P. R. Soc. Lond. B-Bio., 174, 135-154, https://doi.org/10.1098/rspb.1969.0085, 1969.

Vine, F. J.: Spreading of the Ocean Floor: New Evidence: Magnetic anomalies may record histories of the ocean basins and Earth's magnetic field for $2 \times 10^{8}$ years, Science, 154, 14051415, https://doi.org/10.1126/science.154.3755.1405, 1966.

Wolff, E. W.: The past 800 ka viewed through Antarctic ice cores, Episodes, 31, 219-221, https://doi.org/10.18814/epiiugs/2008/v31i2/005, 2008. 